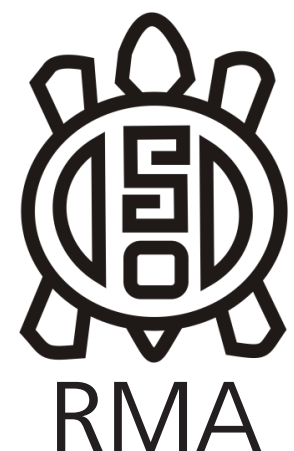

Arqueología

\title{
Peces y coipos: zooarqueología del sitio Valle Hermoso 4 (lago Colhué Huapi, Chubut)
}

\author{
Fish and coypu: zooarchaeological analysis of Valle Hermoso 4 Site
} (Colhué Huapi lake, Chubut province)

\author{
Ariadna Svoboda* y Eduardo Julián Moreno**
}

*CONICET, Instituto de Diversidad y Evolución Austral, Centro Nacional Patagónico, Argentina. E-mail: svoboda@cenpat-conicet.gob.ar ${ }^{* *}$ CONICET, Instituto de Diversidad y Evolución Austral, Centro Nacional Patagónico, Argentina. E-mail: moreno@cenpat-conicet.gob.ar

\begin{abstract}
Resumen
Recientemente se iniciaron investigaciones arqueológicas en el lago Colhué Huapi que resultaron en la detección de una alta densidad de sitios en los sectores noreste y sudoeste. El sitio Valle Hermoso 4 se halla en este último sector, sobre una laguna que en la actualidad se encuentra seca pero que al menos 60 años atrás se hallaba activa. En este trabajo se presentan los resultados obtenidos a partir del análisis zooarqueológico de tres sondeos. La evidencia recuperada señala la explotación predominante de recursos dulceacuícolas (peces, coipos y anátidos) y secundariamente de recursos terrestres (dasipódidos y guanaco). A partir del análisis tafonómico y de rasgos contextuales, se determinó el origen antrópico de los depósitos y se reconoció, en dos sondeos, la alteración de los huesos por la acción del agua. La evidencia aportada por este sitio pone en relevancia a la fauna dulceacuícola sobre el guanaco, recurso comúnmente explotado por cazadores-recolectores del vecino lago Musters. La abundancia de peces (percas y en menor medida pejerrey patagónico) junto con la evidencia artefactual del área (pesos líticos) permiten discutir a la pesca como una actividad intensiva para el Holoceno tardío final.
\end{abstract}

Palabras clave: Patagonia central; recursos dulceacuícolas; ambiente lacustre; Holoceno tardío final.

\begin{abstract}
Recently archaeological investigations in Colhué Huapi Lake resulted in the detection of a high density of sites in the northeast and southwest areas. Valle Hermoso 4 site is located in the last area, in a lagoon which is empty at present but was active at least 60 years ago. This paper presents the results obtained from the zooarchaeological analysis of three surveys. The evidence recovered indicates the predominant exploitation of freshwater resources (fish, coypu and anatids) and secondary of terrestrial resources (Dasypodidae and guanaco). From taphonomic analysis and contextual features, the anthropic origin of the deposits was determined; furthermore, it was recognized the modifications of bones of two assemblages due to water action. The evidence of this site stresses the importance of freshwater fauna over the guanaco, resource commonly exploited by hunter-gatherers of neighboring Lake Musters. The abundance of fish (perch and Patagonian silverside in lesser frequency) with the artifactual evidence of the area (weights stones or sinkers), allows discussing fishing as an intensive activity during the final late Holocene.
\end{abstract}

Keywords: Central Patagonia; freshwater resources; lacustrine environment; Final Late Holocene

Las investigaciones arqueológicas sistemáticas en el lago Colhué Huapi se iniciaron recientemente (Moreno et al. 2015). Se enmarcan en un proyecto desarrollado en el área del bajo de Sarmiento cuyo objetivo general es el estudio de los procesos de diversificación e intensificación económica en cazadores-recolectores, tomando como caso los recursos fluviales (peces, aves y coipos) (Moreno et al. 2007; Moreno y Pérez Ruiz 2010). Los trabajos se centraron inicialmente en la cuenca del lago Musters, donde la prospección de su perímetro permitió detectar más de un centenar de sitios; en algunos de ellos se llevaron a cabo sondeos y excavaciones extensas (Moreno et al. 2007; Moreno y Pérez Ruiz 2010). En general, los sitios son de tamaño pequeño y presentan baja densidad artefactual (a excepción de la localidad Delta del Arroyo Vulcana). Hasta el momento, los estudios zooarqueológicos demuestran la obtención oportunista de los recursos dulceacuícolas, entre los cuales se destacan los peces (perca y en menor medida pejerrey patagónico) (Moreno y Svoboda 2013; Svoboda 2015). La pesca habría sido una actividad poco intensiva, tal como lo demuestra el registro ictioarqueológico y la baja densidad de pesos líticos (de red o línea) recuperados en este lago (Reyes y Svoboda 2016).

La segunda etapa del proyecto se basó en la extensión de las investigaciones al lago Colhué Huapi, el cual contaba con escasos antecedentes arqueológicos (véase Moreno 
et al. 2007); sólo una breve mención de González (1953) cuenta de la existencia de abundantes restos de peces asociados a fogones en el nacimiento del río Chico. Los resultados de los trabajos arqueológicos permitieron registrar varios sitios, abundantes artefactos -entre los que se destacan los pesos líticos-, y material faunístico en superficie y estratigrafía (Moreno et al. 2015). Los sectores del noroeste y del sureste del lago presentaron una alta densidad de sitios destacándose sobre las demás áreas del perilago. En esta contribución, nos centraremos en el sitio Valle Hermoso 4 (VH4) de la localidad arqueológica homónima, ubicada en el sector sudeste sobre la laguna del río Chico (Figura 1). Esta laguna constituía un extenso humedal que conectaba el lago Colhué Huapi con el río Chico, aunque en la actualidad se halla seca. El análisis zooarqueológico preliminar del conjunto faunístico de VH4 indicó una abundancia abrumadora de los recursos dulceacuícolas sobre los terrestres (Moreno et al. 2015). En este trabajo presentamos los resultados finales del análisis zooarqueológico, en tanto que los objetivos planteados son: evaluar la formación y el origen de los conjuntos faunísticos y discutir esta evidencia en el marco de los estudios zooarqueológicos realizados en el área del bajo Sarmiento.
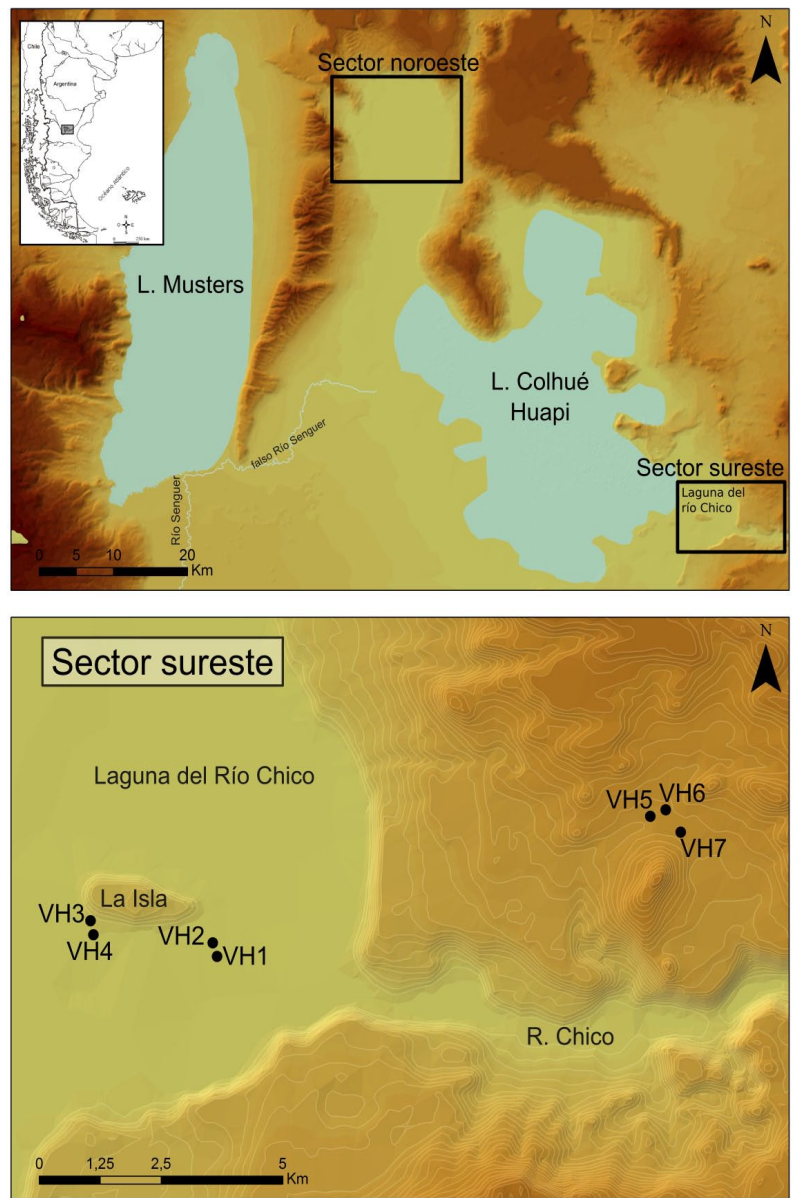

Figura 1. Área de estudio y sitios arqueológicos de la localidad Valle Hermoso $(\mathrm{VH})$

Figure 1. Study area and archaeological sites of Valle Hermoso (VH) localiaty

\section{Marco ecológico del área de estudio}

El lago Colhué Huapi, junto al lago Musters, se halla en una gran depresión de origen tectónico y erosivo denominada bajo de Sarmiento (Figura 1). Recibe sus aguas de un brazo del río Senguer (Falso Senguer) y hasta las décadas de 1930 y 1940 desagotaba en el río Chico. El área se caracteriza por un clima árido con temperaturas que promedian los $9 \mathrm{C}^{\circ}$ y precipitaciones anuales de 150 $\mathrm{mm}$ (Beeskow et al. 1987). La vegetación corresponde al Distrito Central de la Provincia Patagónica cuya fisonomía es la estepa arbustiva con arbustos enanos en cojín y escasas gramíneas (León et al. 1998).

La fauna pertenece al dominio Patagónico (Cabrera y Yepes 1960). Entre las aves terrestres se destaca el choique (Pterocnemia pennata) y entre los mamíferos el guanaco (Lama guanicoe), el puma (Felis concolor), el gato montés (Felis geoffroyi), el zorro gris y colorado (Pseudalopex sp.), el peludo (Chaetophractus villosus), el piche (Zaedyus pichiy), la mara (Dolichotis patagonum) y otros roedores pequeños (Ctenomys sp. y Microcavia australis). La fauna dulceacuícola se compone de peces, entre los que se destacan por su importancia económica la perca (Percichthys trucha) y el pejerrey patagónico (Odontesthes hatcheri); otras especies presentes son el puyén (Galaxias platei) y los bagres Hatcheria macraei y Diplomystes mesembrinus) (Aigo et al. 2008; Ringuelet 1975). En cuanto a las aves acuáticas, la familia Anatidae presenta patos (Anas sp.), cisnes (Cygnus sp.), cauquénes (Chloephaga sp.) y flamenco austral (Phoenicopterus chilensis). También se halla el biguá (Phalacrocorax olivacius) y gallareta (Fulica sp.). Entre los mamíferos se destaca el coipo (Myocastor coypus) y el lobito de río (Lontra provocax).

Variaciones de la línea del paleolago Sarmiento y de la laguna del río Chico

La línea del lago Colhué Huapi ha variado a lo largo del Holoceno y estas fluctuaciones son entendidas en el marco de la dinámica del bajo de Sarmiento (Moreno et al. 2016). Probablemente a fines del Pleistoceno, el bajo fue inundado desde la captura del río Senguer formando un gran cuerpo de agua -denominado paleolago Sarmiento- que incluía a los lagos actuales, y que alcanzó niveles de por lo menos $60 \mathrm{~m}$ sobre el nivel actual del lago Musters (Césari y Simeoni 1994; González Díaz y Di Tommaso 2014). Hacia el Holoceno medio, de acuerdo con la distribución cronológica y altitudinal de sitios arqueológicos, el nivel del paleolago alcanzaba los $30 \mathrm{~m}$ sobre el nivel del lago Musters y cerca del 1600 AP todavía mantenía una altura superior al nivel del mencionado lago (Moreno et al. 2016). Hacia el 1500 AP, se alcanzaría un nivel similar al actual del lago Musters (270 msnm) produciéndose la separación entre ambos cuerpos de agua. Esta evidencia es concordante con los estudios polínicos realizados en el Colhué Huapi que indican un nivel más alto que el actual antes del $1500 \mathrm{AP}$ 
y una disminución hasta un nivel similar al actual. Hacia el 1000 AP, coincidente con la Anomalía Climática Medieval, el nivel bajó con respecto al actual y finalmente se produce un nuevo ascenso, no exento de fluctuaciones (Fabiani et al. 2014; Trivi de Mandri y Burry 2007). Estas fluctuaciones continúan en tiempos históricos produciéndose una sequía casi total del Colhué Huapi a fines de 1990, una recuperación hacia el 2003-2010 y una nueva reducción en la actualidad (Coronato 2003; Llanos et al. 2016). Debido a la diferencia de profundidad entre ambos lagos -20 m promedio para el Musters y 2 m para el Colhué Huapi- sumado a que el Musters recibe directamente las aguas del río Senguer, estas fluctuaciones modernas prácticamente no afectaron a este último lago.

En la laguna del río Chico, donde se encuentra emplazado el sitio VH4, es posible constatar importantes fluctuaciones del nivel de las aguas durante los últimos 150 años. En 1885, tal como se ilustra en el libro de Luis J. Fontana se visualiza un paisaje lagunar con el área totalmente inundada (Fontana 1976 [1886]) (Figura 2a). Estas condiciones se mantenían a mediados del siglo XX de acuerdo con los relatos de los pobladores locales, quienes también mencionan la práctica de pesca recreativa y comercial, y cacerías de coipos. La presencia de una laguna activa en el área de estudio también puede observarse en la carta "Lago Colhué Huapi" del Instituto Geográfico Militar (4569-28) publicada en 1948 (Figura 2b). En la actualidad, la laguna se halla seca y presenta una planicie de inundación cubierta de médanos modernos y vegetación herbácea (Figura 2c). La planicie esta interrumpida por un relicto de meseta conocido localmente como "La Isla", que se une a la antigua costa a través de una barra. Como se observa en la Figura 2b, el relicto no era afectado por el agua, constituyendo así una verdadera isla.

\section{El sitio Valle Hermoso 4}

El sitio VH4 pertenece a la localidad arqueológica homónima, donde fueron registrados cuatro sitios en la planicie de inundación de la laguna del río Chico y tres fuera ella (Figura 1). Se ubica en una franja de médanos en deflación a uno o dos metros de altura sobre la laguna y ocupa un área de $40 \mathrm{~m}$ por $20 \mathrm{~m}$. La distancia con respecto a la actual costa del lago es de $3 \mathrm{~km}$ y con la costa atlántica de aproximadamente $90 \mathrm{~km}$.

Teniendo en cuenta la ilustración en el libro de Fontana (1976 [1886]), VH4 se ubicaría a orillas de la laguna activa en un paisaje dominado por juncales (Figura 2a); probablemente el médano estaría vegetado gracias al aporte de la napa freática más alta. Asimismo, considerando la carta del IGM, el sitio se hallaría separado de tierra firme (Figura 2c).

El material arqueológico de superficie está conformado por abundantes restos óseos, tiestos cerámicos y material lítico. El conjunto artefactual presenta puntas triangulares pedunculadas microlíticas, manos de molinos, raspadores, raederas, lascas, núcleos y pesos líticos. Estos últimos se tratan de rodados chatos con muesca en lados opuestos sobre el eje transversal hallados en concentraciones ${ }^{1}$.

Los trabajos de excavación consistieron en la realización de cuatro sondeos de un metro de lado, los cuales son descriptos a continuación.

- Sondeo 1 (VH4-S1) (profundidad: $30 \mathrm{~cm}$ ). Se ubica en un sector alto del sitio. Se planteó en un sector donde se hallaban algunos restos óseos expuestos. En estratigrafía se hallaron carbones, restos óseos, cáscaras de huevo, material lítico -incluyendo un pedúnculo de una punta microlítica- y un fragmento de cerámica. Varios de los restos óseos de peces se encontraron en posición de vida (e.g arco branquial, dentarios articulados y vértebras). La matriz sedimentaria es arenosa.

- Sondeo 2 (VH4-S2) (profundidad: $5 \mathrm{~cm}$ ). Ubicado en un sector bajo del sitio; se planteo sobre una concentración superficial de materiales óseos adyacente a un relicto de suelo hidromórfico. Se recuperaron restos óseos y materiales líticos superficiales y subsuperficiales. Por debajo de los materiales arqueológicos se halló una capa de arena amarillenta estéril.

- Sondeo 3 (VH4-S3) (profundidad: 25 cm). Adyacente al

${ }^{1}$ Los pesos líticos no fueron recolectados durante los trabajos de campo.
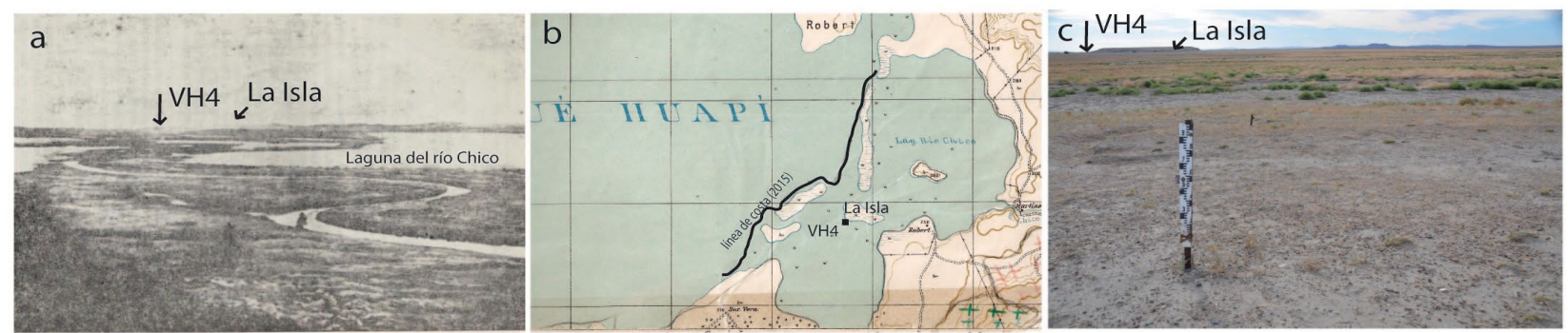

Figura 2. Fluctuaciones de la laguna del río Chico en relación a Valle Hermoso 4. a) paisaje de la laguna del río Chico y del nacimiento del mismo río a fines del siglo XIX (Fontana 1976 [1886]); b) sector sudoeste de la carta geográfica "Lago Colhué Huapi" (Instituto Geográfico Militar 4569-28- año 1948); c) paisaje actual de la laguna del río Chico

Figure 2. Fluctuations of the Chico River Lagoon in relation to Valle Hermoso 4 site. a) landscape of the Chico River Lagoon and the Chico river source in the late nineteenth century (Luis J. Fontana 1976 [1886]); b) southwest area of the map "Lago Colhué Huapi" (Instituto Geográfico Militar 4569-28- published in 1948); c) present landscape of the Chico River Lagoon 
sondeo anterior, se realizó sobre el relicto de suelo. Los materiales (carbones, óseo y lítico) aparecían incluidos en el suelo hidromórfico. Es de aclarar que en este sector el suelo presenta mayor proporción de arena y menor desarrollo que en otros sectores.

- Sondeo 4 (VH4-S4) (profundidad: $5 \mathrm{~cm}$ ). Se trata de un muestreo alejado dos metros al este de los anteriores. Solo presentó materiales (restos de peces, pequeños fragmentos de cascaras de huevo y microlascas) en superficie. Ya que la distribución se corresponde con una lengua de médano vivo y por hallarse en dirección opuesta al viento predominante con respecto a las otras concentraciones, estos huesos habrían sido transportados por el viento desde otros sectores del sitio y posiblemente seleccionados por su bajo peso.

La estratigrafía general del sitio está compuesta por una capa arenosa de color amarillo compactada y sobre ésta, un suelo hidromórfico cubierto por médanos de arena color gris claro. El suelo hidromórfico ${ }^{2}$ presenta una coloración oscura y una estructura prismática de desarrollo variable según el sector. Su formación se asocia a terrenos inundados periódicamente y al desarrollo de vegetación lacustre. Posiblemente se trate del sedimento descripto como "arcilla en terrones" por Trivi de Mandri y Burry (2007: 208) y del que se obtuvieron dataciones de $1040 \pm 70$ y $920 \pm 35$ AP. Por debajo de este, las autoras dataron una capa de arcilla en $1586 \pm 40 \mathrm{AP}$.

En el sector Este (sondeos VH4-S2, VH4-S3 y VH4-S4), la erosión llega hasta el suelo hidromórfico y las arenas amarillas. En el sector Oeste (sondeo VH4-S1), separado por $30 \mathrm{~m}$ del sector anterior, la erosión no profundizó por debajo del médano por lo que no es posible asegurar que debajo del mismo se encuentre el suelo hidromórfico. Es decir que, si bien en otros sectores esta secuencia ocurre no puede descartase la contemporaneidad entre el suelo y el médano. Esto dificulta la interpretación de la cronología relativa de $\mathrm{VH} 4-\mathrm{S} 1$ respecto de los $\mathrm{VH} 4-\mathrm{S} 2$ y $\mathrm{VH} 4-\mathrm{S3}$, no pudiendo definirse si se trata o no de dos componentes.

Si bien no contamos aún con fechados radiocarbónicos es posible estimar la cronología de ocupación de VH4. En primer lugar, de acuerdo a su altimetría (inferior al nivel actual del Musters) y teniendo en cuenta el modelo de descenso del paleolago Sarmiento (Moreno et al. 2016), su ocupación sería posterior a la separación de los lagos, luego del 1500 AP. En segundo lugar, dada la abundancia de fauna dulceacuícola es poco probable que los componentes correspondan al momento de la Anomalía Climática Medieval (ca. 900 AP), momento en el que el lago estaría muy reducido o completamente seco. En tercer lugar, no se han hallado materias primas o artefactos de origen europeo (metal, vidrio, cerámica

2Determinado por el Dr. Pablo Bouza (CONICET, CENPAT, Instituto Patagónico Para el Estudio de los Ecosistemas Continentales). alóctona) ni animales domésticos (vaca, caballo), lo que sugiere que el sitio se formó con anterioridad a la época en que la interacción con los europeos fue más intensa, es decir, antes del siglo XVIII (250 AP). A su vez, la alta frecuencia de artefactos tallados no se corresponde con las expectativas de sitios de momentos históricos (Castro 2010:414-415). En suma, esto sugeriría una ocupación para el Holoceno tardío final entre dos posibles períodos: 1500-1000 o 800-250 AP.

La presencia de cerámica en VH4 es de utilidad para afinar la cronología de ocupación al segundo período (800-250 AP). Si bien las dataciones más antiguas para la cerámica en Patagonia central corresponden a ca. 1250 AP, la mayoría son más tardías (Schuster 2011:70). En un futuro será importante corroborar esta inferencia con dataciones radiocarbónicas; sin embargo, al estado actual de la investigación la asignación temporal al Holoceno tardío final es suficiente.

\section{Materiales y métodos}

Fueron analizados 16.399 restos óseos correspondientes a los sondeos VH4-S1, VH4-S2 y VH4S3. El conjunto faunístico de VH4-S4 no fue considerado ya que los restos hallados podrían corresponder a una acumulación eólica tal como se mencionó anteriormente. Para la recuperación de los restos de vertebrados pequeños, en el campo se emplearon zarandas de malla fina $(1,2 \mathrm{~mm})$ y agua para facilitar la disolución de terrones. Se embolsó el fondo de zaranda y luego, en laboratorio, se utilizaron tres tamices superpuestos de $3 \mathrm{~mm}, 2 \mathrm{~mm}$ y $1 \mathrm{~mm}$ para separar los pequeños restos.

El análisis zooarqueológico consistió en la identificación taxonómica y anatómica utilizando la colección de referencia del Laboratorio de Arqueología del Instituto de Diversidad y Evolución Austral (Puerto Madryn). En esta contribución se excluye a los microroedores, cuyo análisis se encuentra en curso. Se consideró "identificado" a los restos que pudieron ser asignados al menos a la categoría Clase. En este nivel los especímenes de ave y mamífero se discriminaron de acuerdo al peso. En este sentido, para las aves se empleó la clasificación de Giardina (2012): pequeña (Columbidae y Passeriformes), mediana (la mayoría de las aves acuáticas terrestres y marinas) y grande (choique). Para mamíferos se utilizaron las categorías propuestas por Mengoni Goñalons (1999), los cuales se clasifican en pequeño ( $<3 \mathrm{~kg}$ ), mediano- pequeño (entre 3 y 15 kg; aquí se incluyó al coipo y la mara); medianogrande (entre 15 y $50 \mathrm{~kg}$ ) y grande $(>50 \mathrm{~kg}$ ).

Las medidas de cuantificación empleadas para determinar la abundancia taxonómica fueron el NISP y el MNI (Grayson 1984; Klein y Cruz Uribe 1984; Lyman 1994). Asimismo, se calculó el NSP (Número de Especímenes) que abarca todos los ítems de un conjunto faunístico y el NUSP que incluye a los fragmentos no identificados 
taxonómicamente ni anatómicamente (Lyman 2008). En cuanto a la estimación del MNI de mamíferos y aves se consideraron la lateralidad y el estado de fusión (Mengoni Goñalons 1999); en tanto que para los peces se aplicó el criterio de lateralidad en el otolito sagital.

Las unidades de medida utilizadas para evaluar las frecuencias relativas de partes esqueletarias fueron el MNE, MAU y MAU \% (Binford 1984). Para el cálculo del MNE de mamíferos y aves se contemplaron la lateralidad y las zonas diagnósticas (Binford 1984; Mengoni Goñalons 1999) y para los peces se siguió con los lineamientos metodológicos planteados por Zangrando (2009: 134140) que presenta variantes analíticas según las distintas partes anatómicas. En este sentido, para los elementos del cráneo se aplicó el criterio de lateralidad y luego se sumó la frecuencia de MNE de ambos lados (derecho e izquierdo) para obtener el MNE final de cada unidad anatómica. En tanto que en los elementos del poscráneo, el procedimiento no consideró la lateralidad.

El análisis de las variables tafonómicas para evaluar la acción de los agentes naturales y antrópico fue aplicado al total de especímenes (NSP). Respecto a la meteorización se contemplaron los atributos definidos por Behrensmeyer (1978) para mamíferos mayores a 5 kilos; por Muñoz y Savanti (1998) para aves, y por Zangrando (2009) y Svoboda y Moreno (2014) para peces. Otras variables consideradas fueron abrasión sedimentaria, marcas generadas por acción de animales (roedores y carnívoros), depósitos de manganeso y carbonato, marcas de raíces, entre otras (Gutiérrez y Kaufmann 2007; Lyman 1994; entre otros). La fragmentación general de los conjuntos fue evaluada mediante el índice NSP/NISP (Lyman 2008); se evaluó también la fragmentación en los taxones más representados: para los peces se empleo el índice de fragmentación Weighted Mean Index o WMI (Zohar et al. 2001) y para estos y los coipos el índice NISP/MNE (Lyman 1994). La evaluación de la termoalteración se basó en la apariencia macroscópica a partir del color (Shipman et al. 1984, en Mengoni Goñalons 1999). Finalmente, para la identificación de huellas de procesamiento se consideró el tipo y su ubicación en el hueso (Mengoni Goñalons 1999). Los especímenes fueron analizados a nivel macroscópico y en algunos casos se condujeron análisis microscópicos utilizando lupa binocular (ZEISS 50x).

\section{Resultados}

VH4-S1

La proporción de especímenes asignados a alguna categoría taxonómica es de 81,2 \% (NISP=11.915) (Tabla 1). Predominan los peces (NISP\% $=94,51)$ con un total de 11.257 especímenes, de los cuales 5.104 (45,4 \%) fueron identificados anatómicamente y asignados a alguna especie, $4.164(36,9 \%)$ corresponden a fragmentos indeterminados ${ }^{3}$ y $1.989(17,7 \%)$ fueron identificados

\footnotetext{
${ }^{3}$ Comprende aquellos fragmentos no asignados a alguna categoría
}

a nivel anatómico. Estos últimos corresponden a costilla $(n=1.077)$, vértebras $(n=386)$, espinas $(n=163)$, huesos del arco branquial $(n=122)$ y fragmentos del neurocráneo $(\mathrm{n}=209)$. Predomina $P$. trucha $(\mathrm{NISP}=4811)$ con un $\mathrm{MNI}$ de 209 estimado a partir del otolito, seguido por 0 . hatcheri $(\mathrm{NISP}=281)$ con un $\mathrm{MNI}$ de 11 calculado sobre el mismo elemento (Tabla 1). Con respecto a la frecuencia esqueletal, en la perca se observan elementos tanto del cráneo (MNE\%= 22,4) como del poscráneo (MNE\%= 77 ,6) con una sobrerrepresentación del otolito (Figura 3a). En el pejerrey patagónico se manifiesta el mismo patrón: están presentes los huesos craneales (MNE\%= 13,7) y poscraneales $(\mathrm{MNE} \%=87,3)$ y el otolito presenta el valor máximo valor (MAU\%=100) seguido por el basioccipital (MAU\%= 66,6), vértebras (MAU\%= 44,7) y en menor medida otros huesos del cráneo.

En segundo lugar, se hallan los mamíferos (NISP\%= 4,9). Se destaca $M$. coypus (NISP $=96)$ de los cuales se contabilizaron tres individuos a partir del atlas (Tabla 1). La frecuencia anatómica se basa en un predominio de elementos del esqueleto apendicular (MNE\%=82,4) sobre el axial (MNE\%=17,5) y algunos elementos aparecen más representados (cráneo, mandíbula, pelvis y cúbito) (Figura 3b). No hay covariación entre el MAU\% y los valores de rendimiento anatómico elaborados para coipo (León y Bonomo 2011) ya que los coeficientes presentaron valores no significativos con respecto al MUI\% $\left(r_{s}=-0,1\right.$ $p>0,05)$ y al GUI\% $\left(r_{s}=-0,2 p>0,05\right)$. Los especímenes asignados a mamífero mediano-pequeño (NISP= 35), compuestos mayormente de vértebras, costilla y diáfisis, corresponderían a coipo. En menor proporción los dasipódidos (NISP=260), Z. pichiy (NISP=27) y C. villosus $(\mathrm{NISP}=22)$ presentan únicamente placas dérmicas (Tabla 1). Finalmente, algunos especímenes fueron atribuidos a L. guanicoe (NISP=21) y se consignó un $\mathrm{MNI}$ de dos individuos adultos a partir de la escápula (Tabla 1). El patrón esqueletal presenta el predominio de la escápula (MNE=4; MAU\%=100) y del cráneo (MNE=2; MAU\%=50). Con un MAU\% menor a 25 se encuentran representados elementos axiales (vértebras) y apendiculares (tibia, metapodios y falanges). La categoría de los mamíferos grandes (NISP $=65)$ se compone mayormente de astillas que corresponderían a guanaco.

Las aves son poco frecuentes (NISP\%=0,53). Se identificó únicamente la familia Anatidae (NISP=9), con un MNI de 4 calculado a partir del coracoides (Tabla 1). Los individuos podrían corresponder a dos patos y dos cisnes ya que al comparar los coracoides con los de las muestras de referencias se hallaron similitudes en el tamaño de esos géneros. Las partes anatómicas corresponden al esqueleto apendicular; con mayor frecuencia se halló al coracoides (MNE=4; MAU\%=100) y la escápula (MNE=4; MAU\%=100), seguidos por el húmero (MNE=2; MAU\%=

taxonómica de menor inclusividad que Clase (e.g. subclase, género o especie). Esto se aplica a los demás conjuntos de peces de los sondeos VH4-S2 y VH4-S3. 
50) y tibiotarso (MNE=2; MAU\%= 50), y en menor medida radio y ulna $(\mathrm{MNE}=2 ; \mathrm{MAU} \%=25)$, carpometacarpo $(\mathrm{MNE}=1 ; \mathrm{MAU} \%=25)$ y tarsometatarso $(\mathrm{MNE}=1$; MAU\%= 25). Es factible que los especímenes atribuidos a la categoría ave mediana indeterminada (NISP=45) pertenezcan a los anátidos. Las partes anatómicas corresponden a elementos axiales (vértebras, sinsacro y costillas) y apendiculares (diáfisis y falanges).

Por último, en una baja frecuencia $($ NISP\% $=0,03)$ se hallaron restos del reptil Liolaemus sp. (NISP $=4)$ de los cuales se contabilizaron tres individuos (Tabla 1). Los restos corresponden únicamente a mandíbulas y maxilares.

\section{Preservación y alteraciones}

Como lo demuestra el índice NSP/NISP la fragmentación general del conjunto es baja; lo mismo ocurre con los índices NISP/MNE de fragmentación de peces y coipo (Tabla 2). Con respecto a la meteorización, en el conjunto de peces sólo un 0,4\% $(n=52)$ de los especímenes presenta exfoliaciones y agrietamientos. En las aves el $70,5 \%(n=36)$ se halla en el Estadio 0, 19,6\% $(n=10)$ en el Estadio 1 y 9,8 \% ( $n=5)$ en el Estadio 2. En cuanto a los mamíferos, el $71 \%(n=71)$ de los especímenes se distribuyen entre los Estadios 0 y 1, y los restantes ( $n=$ 29) entre los Estadios 2, 3 y 4. Cabe mencionar que los restos que se hallaban en superficie $(n=336)$ presentan blanqueamiento por exposición solar y, a su vez, exhiben los estadios más avanzados de meteorización.

Como se observa en la Tabla 3 las marcas de raíces (4,1\%) y depósitos de óxido de manganeso (3,1\%) son las únicas variables registradas en los tres grupos taxonómicos (peces, aves y mamíferos). Si bien su frecuencia relativa es baja, su presencia da cuenta de una cierta edafización.

En el conjunto de peces se observó deformación en vértebras de perca $(0,7 \%)$ y en menor medida en pejerrey patagónico (0,03 \%) (Tabla 3). Asimismo, el índice de fragmentación WMI para perca es de 66,9 y para pejerrey patagónico es de 91,1 (Tabla 2). Esto señala que la menor abundancia taxonómica de la segunda especie no responde a factores de preservación diferencial interespecífica.

En la Tabla 4 se presenta la frecuencia de alteraciones antrópicas en los grupos taxonómicos. Entre los peces se observa termoalteración $(10,5 \% ; n=1158)$ que se distribuyen en el esqueleto craneal y poscraneal, en este último la mayoría de los alterados corresponden a vértebras $(n=260)$. Sólo una diáfisis de ave mediana indeterminada evidenció huellas de procesamiento que corresponden a dos cortes oblicuos y cortos y a dos cortes transversales que cubren casi la totalidad de la circunferencia del hueso (Figura 4a). El conjunto del coipo y los mamífero mediano-pequeño presentan daño térmico $(13,7 \% ; n=18)$ en los elementos del esqueleto apendicular y un espécimen con huellas antrópicas $(0,7$ $\% ; n=1)$. Este último presenta dos cortes transversales que abarcan la circunferencia de una diáfisis (Figura 4b). Las placas de los dasipódidos y del piche sólo presentan termoalteración $(2,9 \% ; n=9)$. Finalmente, las astillas de mamífero grande indeterminado, atribuibles a guanaco, presentaron evidencias de combustión (16,2\%; $n=14)$ y de procesamiento $(6,2 \% ; n=6)$; estas últimas vinculadas a negativos de impacto.

\section{$\mathrm{VH} 4-\mathrm{S} 2$}

El $64,5 \%(N I S P=428)$ de los restos fue atribuido a

Tabla 1. Composición y abundancia taxonómica de los conjuntos faunísticos de Valle Hermoso 4

Table 1. Taxonomic composition and abundance of faunal assemblages of Valle Hermoso 4 site

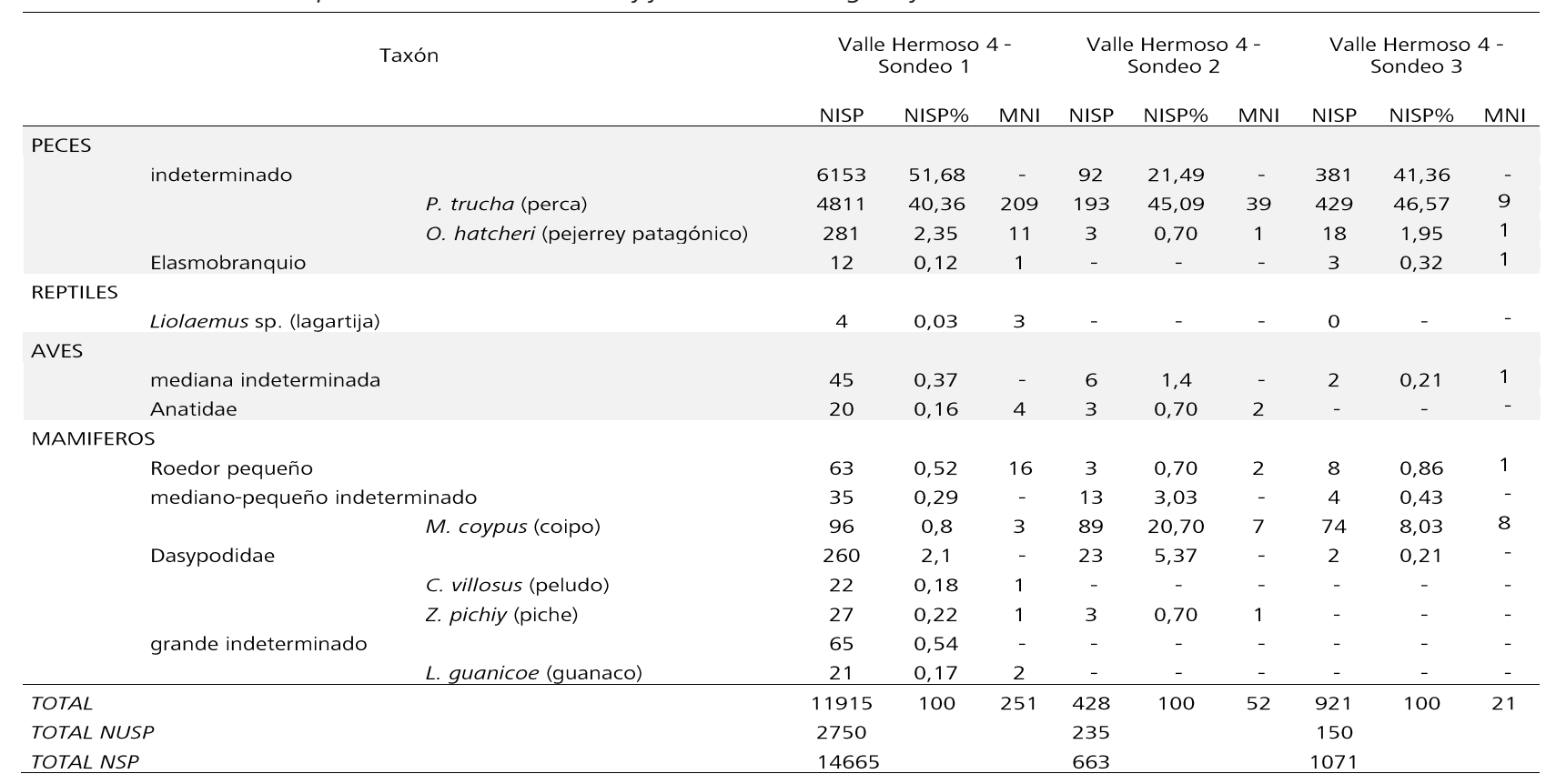


a

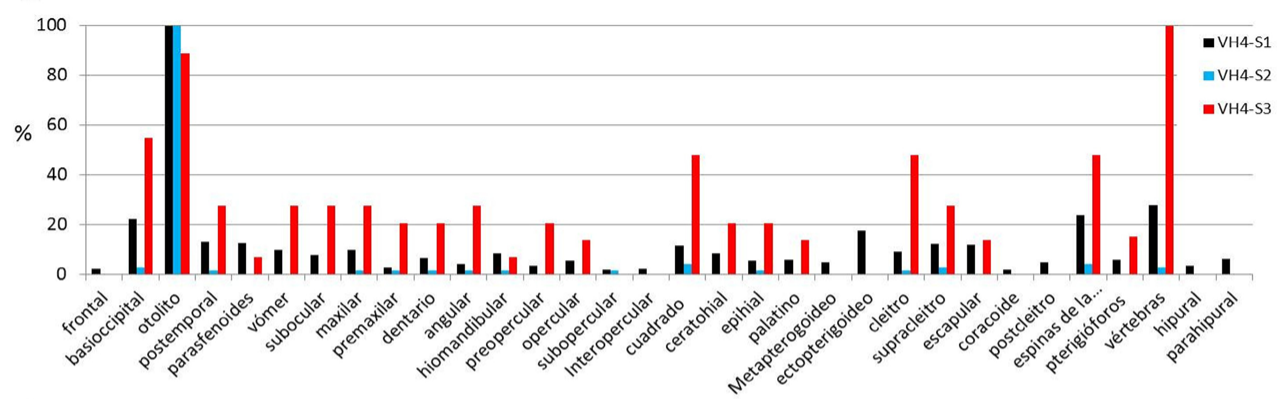

b

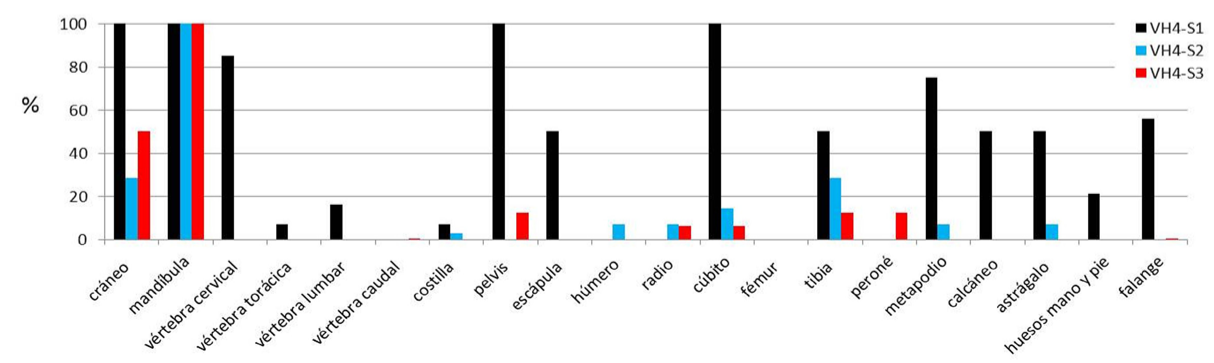

Figura 3. Frecuencia anatómica (MAU\%) de perca (a) y coipo (b)

Figure 3. Frequencies of perch (a) and coypu (b) esqueletal parts (MAU\%)

Le siguen los mamíferos $($ NISP\% $=30,5)$, entre los que predominan la especie dulceacuícola $M$. coypus (NISP= 89) con un MNI de siete individuos estimados a partir de la mandíbula (Tabla 1). Se halla representado el esqueleto axial (MNE\%= $58,3)$ como el apendicular $(\mathrm{MNE} \%=41,6) ; \sin$ embargo, la mandíbula alguna categoría taxonómica (Tabla 1). Prevalecen los peces $(\mathrm{NISP} \%=67,28)$ cuyo conjunto se compone de 288 especímenes, de los cuales 196 (68,0 \%) fueron identificados taxonómicamente y anatómicamente, 27 (9,4 \%) determinados anatómicamente (pertenecen a fragmentos del neurocráneo y costillas) y los restantes 65 $(22,6 \%)$ corresponden a fragmentos no identificados. Las especies identificadas son la perca (NISP=193) con un MNI de 39 estimado a partir del conteo de otolitos y pejerrey patagónico $(\mathrm{NISP}=3)$ representado por un individuo. Como se observa en la Figura 3a, la representación anatómica de la perca muestra una sobrerrepresentación del otolito mientras el resto de los elementos se presentan en muy baja frecuencia; además los elementos del cráneo (MNE\%= 57,1) son más frecuentes que los del poscráneo (MNE\%= 42,8). Por su parte, el pejerrey patagónico aparece representado por vértebras.

Tabla 2. Índices de fragmentación

Table 2. Fragmentation índices

\begin{tabular}{lccc}
\hline & VH4-S1 & VH4-S2 & VH4-S3 \\
\hline NSP/NISP & 1,2 & 1,5 & 1,2 \\
NISP/MNE peces & 1,8 & 1,6 & 2,7 \\
NISP/MNE coipo & 1,2 & 3,7 & 3,2 \\
WMI perca & 66,9 & 67,7 & 64,4 \\
WMI pejerrey patagónico & 91,1 & - & 88,8 \\
\hline
\end{tabular}

Tabla 3. Modificaciones naturales

Table 3. Natural modifications

\begin{tabular}{lcccccc}
\hline \multirow{2}{*}{ Variable tafonómica } & \multicolumn{2}{c}{ VH4-S1 } & \multicolumn{2}{c}{ VH4-S2 } & \multicolumn{2}{c}{ VH4-S3 } \\
& NISP & $\%$ & NISP & $\%$ & NISP & $\%$ \\
\hline Marcas de carnívoros & - & - & - & - & - & - \\
Marcas de roedores & - & - & 3 & 0,7 & - & - \\
Marcas de raíces & 482 & 4,1 & 13 & 3,2 & 21 & 2,3 \\
Óxido de manganeso & 352 & 3,1 & - & - & - & - \\
Abrasión sedimentaria & - & - & 46 & 11,4 & 55 & 5,9 \\
Deformación (peces) & 92 & 0,7 & - & - & 8 & 0,9 \\
\hline
\end{tabular}

es el elemento sobrerrepresentado (Figura 3b). No hay covariación entre el MAU\% y los valores de rendimiento anatómico MUI\% $\left(r_{s}=-0,2 p>0,05\right)$ y GUI\% $\left(r_{s}=-0,1\right.$ $p>0,05)$ elaborados para coipo. Por su parte, la categoría de mamífero mediano-pequeño (NISP=13) se encuentra representado por fragmentos de diáfisis que corresponderían a coipo. Los dasipódidos (NISP=23) y Z. pichiy $(\mathrm{NISP}=3)$ presentan únicamente placas dérmicas.

Por último, las aves se presentan en una baja frecuencia $(\mathrm{NISP} \%=2,1)$. Entre estas se identificaron especímenes de anátidos (NISP $=3$ ) que corresponde a dos individuos: posiblemente un pato y un cisne, cada uno estimado a partir del coracoides (Tabla 1). Los especímenes de ave mediana $(\mathrm{NISP}=6)$, corresponden a diáfisis.

La fragmentación general (NSP/NISP) del conjunto es levemente más alta que en el anterior conjunto (Tabla 2). El conjunto de los peces presenta baja fragmentación $(1,6)$, en particular el valor WMI de perca es de $67,7 \%$ y el de pejerrey patagónico no fue calculado porque solo son tres especímenes. Los restos de coipo exhiben un índice NISP/MNE más alto $(3,7)$ (Tabla 2). Por otro lado, la meteorización en los peces es baja registrándose el 1,04 $\%(n=3)$ con exfoliación o agrietamiento; en las aves y mamíferos el $100 \%$ se halla en el Estadio 0.

El 85,3\% del NSP presenta coloración marrón oscuro, lo cual obstaculiza la observación de variables como la termoalteración y el óxido de manganeso. Como se observa en la Tabla 3, la variable más frecuente es la abrasión sedimentaria (11,4 \%) detectada en peces, aves, coipos y mamífero mediano-pequeño. Los especímenes presentan una superficie ósea brillante y suave al tacto, criterios que permitieron atribuirlos al Estadio 1 de abrasión definido por Gutiérrez y Kaufmann (2007). Un espécimen con mayor daño presentaba la remoción del

\section{Preservación y alteraciones}




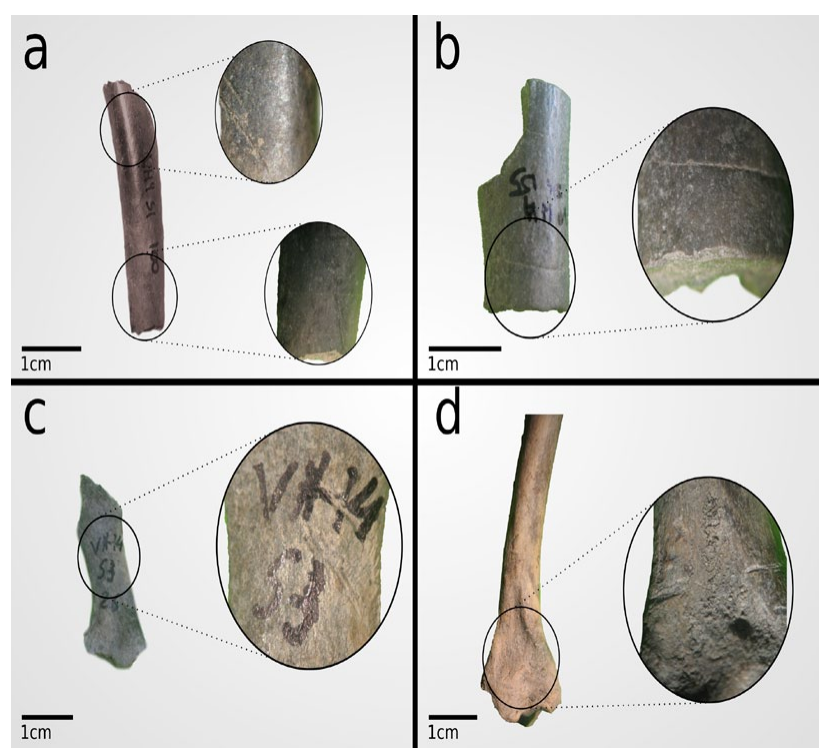

Figura 4. Modificaciones antrópicas. a) ave mediana indeterminada (100-VH4-S1); b) diáfisis de mamífero medianopequeño indeterminado (155- VH4-S1); c) pelvis de coipo (26-VH4-S3); y, d) tibia de coipo (20-VH4-S3)

Figure 4. Anthropic modifications. a) diaphysis of a medium bird (100-VH4-S1); diaphysis of a small- medium mammal (155-VH4-S1); pelvis of coypu (26-VH4-S3); d) tibia of coypu (20-VH4-S3)

tejido externo por lo cual se lo asignó al Estadio 3. Otras variables registradas corresponden a marcas de raíces $(3,2 \%)$ que se presentan en los tres grupos taxonómicos, y la de acción de roedores $(0,7 \%)$ registrada en los especímenes de aves y mamíferos (Tabla 3).

En cuanto a las alteraciones culturales, únicamente se registraron evidencias de combustión en el conjunto de los peces $(1,04 \%)$ que corresponden a tres otolitos carbonizados (Tabla 4).

\section{$\mathrm{VH} 4-\mathrm{S3}$}

El $85,9 \%(\mathrm{NISP}=921)$ de los restos fue identificado taxonómicamente (Tabla 1). Predominan los peces $($ NISP\% $=90,2)$, cuyo conjunto está compuesto por 831 especímenes, entre los cuales 450 (54,1\%) fueron asignados a una categoría taxonómica y anatómica, $125(27,7 \%)$ corresponden a una categoría anatómica (costillas, vértebras, arco branquial, fragmentos del neurocráneo) y 256 (30,8 \%) no fueron identificados. La composición taxonómica comprende perca (NISP= 429), con un MNI de 9 contabilizado a partir del otolito, y pejerrey patagónico (NISP=18) al que fue asignado un solo individuo. En lo que respecta a la representación de partes esqueletales, la perca presenta el cráneo (MNE\%=61,8) y el poscráneo (MNE\%= 42,8) con una sobrerrepresentación de las vértebras y el otolito (Figura 3a). Las partes anatómicas del pejerrey patagónico se corresponden con vértebras y un basioccipital.

Le sigue el coipo (NISP= 74) cuyo MNI es de 8 calculado a partir de la mandíbula (Tabla 1). El perfil anatómico muestra el esqueleto axial (MNE\%=60,8) y el apendicular (MNE\%= 39,2), y se encuentra sobrerrepresentada la mandíbula (Figura 3b). No hay covariación entre el MAU\% y los valores de rendimiento anatómico MUI\% $\left(r_{s}=-0,1\right.$ $p>0,05)$ y al GUI\% $\left(r_{s}=-0,1 p>0,05\right)$. La categoría de mamífero mediano-pequeño indeterminado ( $\mathrm{NISP}=4)$ se corresponde con fragmentos de huesos articulares.

Con una baja frecuencia se encuentran las aves y los dasipódidos (NISP\% =2,1 cada uno). La primera categoría corresponde a un ave mediana (NISP $=2$ ) representada por un sinsacro y un fragmento de diáfisis (Tabla 1). Respecto a los dasipódidos solo se hallaron placas dérmicas (NISP=2).

\section{Preservación y alteraciones}

La fragmentación general (NSP/NISP) del conjunto es baja (Tabla 2). Teniendo en cuenta las Clases taxonómicas, los peces presentan un índice de fragmentación de 2,7 en tanto que el índice WMI para perca es de 64,4 y el de pejerrey patagónico es de 88,8 , lo cual demuestra que la integridad de la segunda especie no se halla afectada (Tabla 2). La fragmentación del coipo de 3,2 es similar a la de VH4-S2 (Tabla 2).

La meteorización es baja en general: ningún espécimen del conjunto de peces demostró exfoliación o agrietamiento; los dos especímenes de aves se hallaban en el Estadio 0;

\begin{tabular}{|c|c|c|c|c|c|c|c|c|}
\hline \multirow{2}{*}{ Taxón } & \multirow{2}{*}{ Región esqueletal (elemento) } & \multicolumn{2}{|c|}{ VH4-S1 } & \multicolumn{2}{|c|}{ VH4-S2 } & \multicolumn{2}{|c|}{ VH4-S3 } & \multirow{6}{*}{$\begin{array}{l}\text { Tabla 4. Modificaciones } \\
\text { antrópicas por grupo } \\
\text { taxonómico. Número de } \\
\text { Especímenes Identificados por } \\
\text { taxón con huellas de corte } \\
\text { (NISPc) y con evidencias de } \\
\text { alteración térmica (NISPt) }\end{array}$} \\
\hline & & NISPt & NISPC & NISPt & NISPC & NISPt & NISPC & \\
\hline \multirow{3}{*}{$\begin{array}{l}\text { Peces indeterminados, } P \text {. } \\
\text { trucha y } 0 \text {. hatcheri }\end{array}$} & CRÁNEO & 201 & 0 & 3 & 0 & 0 & 0 & \\
\hline & $\begin{array}{l}\text { POSCRÁNEO (costilla, vértebra, } \\
\text { pterigióforo y espinas aleta dorsal y anal) }\end{array}$ & 357 & 0 & 0 & 0 & 0 & 0 & \\
\hline & indeterminado & 600 & & 0 & 0 & 0 & 0 & \\
\hline $\begin{array}{l}\text { Ave mediana } \\
\text { indeterminada y Anatidae }\end{array}$ & APENDICULAR (diáfisis) & 0 & 1 & 0 & 0 & 0 & 0 & \\
\hline $\begin{array}{l}\text { Mamífero mediano pequeño } \\
\text { indeterminado y } M \text {. coypus }\end{array}$ & $\begin{array}{l}\text { APENDICULAR (cubito, tibia, calcáneo, } \\
\text { metapodio, falange y diáfisis) }\end{array}$ & 18 & 1 & 0 & 0 & 0 & 2 & Table 4. Anthropic \\
\hline Dasypodidae y Z. pichiy & placa dérmica & 9 & 0 & 0 & 0 & 0 & 0 & modification by taxonomic \\
\hline \multirow[t]{2}{*}{$\begin{array}{l}\text { Mamífero grande } \\
\text { indeterminado y L. guanicoe }\end{array}$} & APENDICULAR (tarsiano y astillas) & 14 & 6 & 0 & 0 & 0 & 0 & $\begin{array}{l}\text { Specimens per taxon with } \\
\text { cut marks (NISPC) and with }\end{array}$ \\
\hline & Total & 1199 & 8 & 3 & 0 & 0 & 2 & burning damage (NISPt) \\
\hline
\end{tabular}


$y$, el 94,8\% ( $n=37)$ de los restos de mamífero medianopequeño y coipo se hallaban en el Estadio 0 y los restantes $5,2 \%(n=2)$ en el Estadio 2.

El 82,3 \% del NSP presenta coloración marrón oscuro. Como se observa en la Tabla 3 la variable tafonómica más frecuente es la abrasión sedimentaria (5,9\%) que fue registrada en 55 especímenes de peces y coipos. Los especímenes presentan una patina brillosa y una textura suave (Estadio 1 de abrasión sedimentaria). También se observaron improntas de raíces $(2,3 \%)$ y en el conjunto de los peces algunas vértebras de perca se hallaban deformadas por aplastamiento (0,9\%) (Tabla 3).

Con relación al procesamiento antrópico, no se hallaron evidencias de combustión en ningún grupo taxonómico, pero sí de huellas de corte (Tabla 4). Estas fueron observadas en dos especímenes de coipo (2,5\%): uno de ellos corresponde a una pelvis, el cual presentaba huellas de corte en ambas caras (Figura 4c); el otro se trata de una diáfisis distal de tibia (Figura 4d). Por su ubicación en el hueso, las segundas corresponden a tareas de cuereado (Escosteguy y Vigna 2010).

\section{Discusión}

Origen y formación de los conjuntos faunísticos En primer lugar, la fragmentación general de los tres conjuntos no presenta diferencias (Tabla 2), lo que permitió identificar taxonómicamente una alta proporción de restos: $81 \%$ en $\mathrm{VH} 4-\mathrm{S} 1,64 \%$ en $\mathrm{VH} 4-\mathrm{S} 2$ y $85 \%$ en VH4-S3. Lo mismo ocurre con los índices de fragmentación de peces que son similar en los tres muestreos $(1,8 ; 1,6 \mathrm{y}$ 2,7 respectivamente). En $\mathrm{VH} 4-\mathrm{S} 2$ y $\mathrm{VH} 4-\mathrm{S} 3$ los restos de coipos se hallan más fragmentados.

En referencia a la meteorización ósea, en los tres conjuntos se presenta una baja proporción de restos de peces con evidencias de agrietamientos y exfoliaciones, lo cual sugeriría un rápido enterramiento de los restos (Svoboda y Moreno 2014). Cabe mencionar que en VH4-S1 algunos huesos de peces aparecieron articulados, lo cual también sustentaría la idea de una rápido sepultamiento. En concordancia con el conjunto de peces, los especímenes de aves y mamíferos se hallan en los estadios bajos de meteorización, señalando que no estuvieron expuestos por un tiempo prolongado.

En los tres sondeos se destaca el predominio de los recursos dulceacuícolas (perca, pejerrey patagónico, anátidos y coipo). La abundancia de fauna dulceacuícola esta en concordancia con el escenario ambiental de finales de siglo XIX exhibido por Fontana (1976 [1886]) que muestra a VH4 ubicado en un hábitat lacustre activo (Figura 2a). Esta interpretación se ve reforzada por la presencia de un suelo hidromórfico en un sector del sitio.

Por esta razón los conjuntos faunísticos analizados que estarían asociados a un contexto lacustre deben ser cuidadosamente analizados ya que la acción del agua puede cumplir un rol importante en la formación y el transporte de los huesos (Gutiérrez y Kaufmann 2007; Lyman 1994; entre otros). Esto es particularmente cierto en el caso de los sondeos VH4-S2 y VH4-S3 asociados al suelo hidromórfico. En este sentido, el análisis tafonómico permitió reconocer la acción hídrica: una alta proporción de especímenes (de $85 \%$ a $82 \%$ ) presenta coloración marrón oscuro, característica usual de los huesos que estuvieron bajo condiciones de saturación de agua en contacto con suelos encharcados (Gutiérrez com. pers. 2016). También son frecuentes los especímenes con abrasión sedimentaria tanto en $\mathrm{VH} 4-\mathrm{S} 2$ como en VH4-S3 (11,4\% y 5,9\% respectivamente) que se ve reflejada por una textura suave y una patina brillosa de la superficie ósea. En menor medida se evidenciaron marcas de radículas. Teniendo en cuenta esta evidencia se infiere que los huesos estuvieron en contacto con un suelo en situación de encharcamiento donde, si bien hubo presencia de agua en ciertos episodios, permitió el desarrollo de un suelo con vegetación (evidenciado por las improntas de raíces) con alto contenido de materia orgánica y saturación de agua. Asimismo, la presencia de abrasión sedimentaria estaría reflejando situaciones donde el hueso quedó semisepultado por agua y el movimiento oscilatorio de baja energía (e.g. borde de laguna) generara la abrasión por partículas sedimentarias (Gutiérrez com. pers 2016). Cabe mencionar que el lago Colhué Huapi presenta un alto contenido de materia inorgánica en suspensión (Pizzolon 2003), lo cual facilitarían la abrasión de los huesos.

Por el contrario, la acción hídrica no tuvo incidencia en el conjunto VH4-S1. En principio, los restos óseos se hallaban en una matriz arenosa de origen eólico. A su vez, los especímenes no evidencian abrasión sedimentaria $u$ otros indicios que demuestren una posible afectación de los huesos a contextos de saturación de agua (e.g. color marrón oscuro). La presencia de marcas de raíces y de impregnaciones de óxido de manganeso, señalan condiciones de mayor humedad del contexto inmediato y una cierta edafización del médano vinculable a la presencia de agua en la laguna que elevaría la napa freática. Si bien los dos sondeos afectados por la acción hídrica se hallan a 30 metros de distancia de VH4-S1, las diferentes historias tafonómicas se explicarían por la ubicación altimétrica dentro del sitio. En este sentido, VH4-S1 se halla en una parte alta del sitio que no fue alcanzada por el agua en los momentos en que la laguna del río Chico estaba activa.

En cuanto a la abundancia anatómica del coipo, se observan diferencias entre el patrón del conjunto del sector Oeste con respecto a los conjuntos del sector Este. En el primer sector, el conjuto VH4-S1 muestra una representación integral del esqueleto del coipo, lo cual señala el traslado de las presas completas al sitio; 
asimismo, el patrón esqueletal no varía en función del contenido cárnico. En el segundo sector, los conjuntos de VH4-S2 y VH4-S3 presentan un predominio de mandíbulas. Este patrón no parece responder a la destrucción de huesos mediado por la densidad ósea, ya que los elementos exhiben una buena integridad. En cambio, podría relacionarse con el descarte diferencial de estas partes esqueletarias, específicamente con el aprovechamiento de la lengua y el cerebro; tal como fue inferido a partir de la presencia de elementos craneales en sitios arqueológicos de la cuenca del río Salado (Prov. de Buenos Aires) (Escosteguy et al. 2012). Otra posibilidad que explique el patrón esqueletal diferencial de coipo de ambos sectores del sitio tiene que ver con el efecto del transporte diferencial por la acción hídrica en los conjuntos VH4-S2 y VH4-S3. Cabe recordar, la coloración oscura que presentan la mayoría de los huesos y, especialmente, la existencia de abrasión en varios de ellos. Tal como ha sido demostrado por experimentaciones actualísticos con guanaco ciertos elementos anatómicos presentan una mayor potencialidad de transportabilidad por la acción hídrica (Gutiérrez y Kaufmann 2007). Lo mismo podría haber ocurrido con los elementos de coipo; pero se requieren estudios específicos para ratificar esta explicación.

En relación con el perfil anatómico de perca se observa la representación integral del esqueleto en los conjuntos VH4-S1 y VH4-S3 mientras que en VH4-S2 hay un leve predominio del cráneo. En todos ellos, el patrón es similar al del esqueleto estándar de los peces (Butler 1993) por lo que se infiere una depositación de percas completas a los depósitos. Por otro lado, en los tres conjuntos hay sobrerrepresentación del otolito, aunque en VH4-S3 también de vértebras. Los otolitos son las estructuras más duras de los peces que constituyen una concreción formada por carbonato cálcico cristalizado en aragonito, es por ello que son los menos susceptibles a fragmentarse por diversos factores posdepositacionales. En principio, la supervivencia diferencial de los otolitos, no respondería a la meteorización.

En perfil anatómico de las categorías taxonómicas menos representadas (aves y guanaco) es variable. En los anátidos, se observa la completitud de carcasas en VH4-S1 y en los otros sondeos se observa un leve predominio del esqueleto axial, aunque los especímenes son muy escasos. El guanaco, hallado únicamente en VH4-S1, exhibe mayormente al esqueleto axial (escápula y cráneo), pero la alta cantidad de astillas atribuibles a esta especie da cuenta de la representación integral del esqueleto. Asimismo, la presencia de negativos de impacto en estos elementos sugiere actividades de consumo.

En VH4-S2, además de la acción hídrica, el viento es otro factor de alteración principalmente de los restos de peces, ya que se trata de un muestreo superficial cuyo material se halla expuesto a la acción de agentes subaéreos. Esto se constata a partir de la menor proporción de peces (NISP\%=67) con respecto a VH4-S1 (NISP\%=94) y VH4-S3 $(\mathrm{NISP} \%=90)$. Cabe mencionar que la proporción de restos de coipos de VH4-S2 en relación con el sondeo contiguo VH4-S3 no registra diferencias. La baja frecuencia de restos de peces en $\mathrm{VH} 4-\mathrm{S} 2$ puede relacionarse con los resultados obtenidos de un estudio experimental actualístico realizado en la costa norte de Chubut con huesos de peces, entre ellos perca. Estos permitieron observar la alta dispersión horizontal de los ítems producida por el viento (Svoboda 2016). Si consideramos que en el lago Colhué Huapi el índice de agresividad eólica (valores de 800) es considerablemente mayor al de la zona donde se llevo a cabo la experimentación (valores entre 200 y 400) (Coronato 1994), es posible afirmar el alto impacto de este agente en los conjuntos arqueológicos de superficie, principalmente en referencia a los restos de peces. Es por ello que futuros estudios deberán ser dirigidos a entender el transporte diferencial de elementos, por ejemplo, VH4-S2 donde hay una alta sobrerrepresentación de otolitos.

Con respecto al origen de los depósitos, las evidencias más claras de una formación antrópica provienen del conjunto VH4-S1 que no se encuentra alterado por la acción hídrica ni eólica, tal como lo indica la presencia de huesos articulados de peces. El contexto arqueológico presenta una clara asociación de los restos óseos con carbones y material artefactual (lítico y cerámico). Asimismo, los restos presentan evidencias de procesamiento que se distribuyen en los grupos taxonómicos más representados (peces, aves, coipo y guanaco) aunque no en lagartijas pequeñas (Liolaemus sp.). La presencia de estos reptiles $y$, probablemente los microroedores, se debe a procesos de agregación de origen natural. En cuanto a los dasipódidos, las evidencias de termoalteración fueron registradas en piche, lo cual contribuyen a defender el uso intencional (cocción, descarte en el fuego o uso de los huesos como combustible) de este animal; no obstante, esta variable por sí sola no explica el aprovechamiento antrópico. Por otro lado, la ausencia de alteración térmica en los especímenes de peludo podría sugerir su introducción natural a los depósitos. Cabe mencionar que los hábitos excavadores de los dasipódidos los ubica como un importante agente disturbador de los contextos arqueológicos ocasionada la mezcla de materiales (Frontini y Escosteguy 2012). No obstante, no fueron registradas cuevas en el sitio por lo que descartamos la posible acción de este agente disturbador.

El agente de formación de los depósitos VH4-S2 y VH4-S3 es más dudoso por su historia tafonómica asociada a la acción del agua que podrían sugerir acumulaciones naturales (Stewart 1991). Las evidencias de procesamiento están ausentes en VH4-S2 y son escasas en VH4-S3. No obstante, es usual observar ausencia o baja frecuencia de huellas antrópicas en vertebrados pequeños (Butler 1996; Stahl 1996; Stewart 1991; entre 
otros), lo cual respondería a múltiples causas relacionadas principalmente con el tamaño, un procesamiento limitado y poco intenso, un contacto escaso con los utensilios de corte o la ausencia de utilización de artefactos cortantes (Butler 1996). También, es muy probable que la baja frecuencia de daño térmico pudiera estar oculta por el color marrón obscuro que presentan la mayoría de los especímenes de estos sondeos.

Otros criterios elaborados para peces dan cuenta del origen antrópico de los depósitos VH4-S2 y VH4-S3 (síntesis en Zohar et al. 2001). En primer lugar, la diversidad taxonómica que es baja y se compone por perca y pejerrey patagónico con ausencia de otros taxones litorales de menor importancia económica (puyén y bagres) (Aigo et al. 2008). Además, la alta abundancia de las percas -en relación al pejerrey patagónico (Tabla 1)- no se condice con la proporción natural de percas en ninguna cuenca de Patagonia (Aigo et al. 2008: Figura 2). En segundo término, otro indicador de selección antrópica deriva de las tallas de percas cuya estimación -utilizando modelos de regresión lineal (Svoboda 2013a, 2015)- se encuentra en curso. No obstante, una primera aproximación -por el método de comparación de tamaños de otolitos con la colección de referencia- nos permite estimar un rango de percas más pequeñas ${ }^{4}$ de $20 \mathrm{~cm}$ a $45 \mathrm{~cm}$ de largo total. Este patrón difiere de las tallas acotadas en 25 a $35 \mathrm{~cm}$ de largo observadas en depósitos naturales de perca en la laguna LLancanelo en la provincia de Mendoza (Corbat 2014). Finalmente, no se detectaron marcas de animales predadores acumuladores de los restos. Todo esto, sumado a otros elementos como la presencia de carbones, cerámica y artefactos líticos asociados, permite defender la formación antrópica de los depósitos VH4-S2 y VH4-S3.

\section{Implicaciones para el área del bajo de Sarmiento}

El sitio VH4 funcionó como una base residencial donde se dieron tareas de consumo in situ de peces, aves y coipos, obtenidos en las inmediaciones del sitio. El predominio abrumador de los peces y de fauna dulceacuícola en general por contraposición al escaso registro de recursos terrestres es novedoso para el área de estudio. Los otros recursos explotados son el guanaco y el piche, los cuales se encuentran escasamente representados; cabe mencionar que el NISP del último taxón se encuentra sobrevalorado por la cantidad de placas que presenta un individuo. Frente a la pregunta acerca de cuán representativo es este conjunto arqueofaunístico en la arqueología del Colhué Huapi, cabe considerar al sitio Boliche de Jerez 9 cuyo análisis zooarqueológico preliminar demuestra abundantes restos de fauna dulceacuícola y escasos de guanaco (Moreno et al. 2015). Sin embargo, otros sitios (e.g. Boliche de Jerez 1, Boliche de Jerez 3, Valle Hermoso 1 y Valle Hermoso 2) aparentan una gran abundancia de

${ }^{4}$ Los otolitos arqueológicos son más pequeños con respecto a los ejemplares de la colección de referencia cuya talla inferior es de $20 \mathrm{~cm}$ de largo total, de modo que las percas arqueológicas serían menores a ese largo. huesos de guanacos en superficie. Dado el alto impacto eólico sobre los contextos arqueológicos en el área, es muy probable que en estos sitios existan problemas tafonómicos en detrimento de los restos de peces, tal como fue observado en experimentos actuales (Svoboda 2015, 2016).

Los resultados obtenidos de este trabajo confirman lo inferido en base a observaciones de campo publicado en Moreno y coautores (2015). A su vez, la alta frecuencia de peces es coherente con la existencia de grandes cantidades de pesos líticos -posiblemente de red- hallados en la cuenca (Reyes y Svoboda 2016; Reyes et al. 2016). Toda esta evidencia, sugiere que lo peces constituyeron un recurso sistemáticamente explotado en lago Colhué Huapi.

Al comparar estas evidencias con la de los contextos faunísticos del lago Musters surgen sustanciales diferencias. En primer lugar, pese a casi 10 años de investigaciones orientadas a identificar estrategias de explotación de fauna dulceacuícola (Moreno et al. 2007), no se hallaron en el registro arqueofaunístico ni en el artefactual (pesos líticos) evidencias de utilización importante de peces (Moreno y Pérez Ruiz 2010; Moreno y Svoboda 2013, Svoboda 2015). Cabe mencionar que ambos cuerpos de agua forman parte de la misma cuenca y están separados por menos de $10 \mathrm{~km}$. Está en estudio si se trata de una diferencia en la actividad humana o un problema de formación del registro.

Si bien no contamos con fechados radiocarbónicos, VH4 fue asignado al Holoceno tardío final momento donde es posible confirmar la explotación intensiva de peces junto con otros recursos dulceacuícolas. Teniendo en cuenta las crónicas de viajeros disponibles para Patagonia central y meridional, es notable que en las fuentes escritas no aparece ninguna mención clara a la utilización de peces fluviales y, en al menos un caso, una negación explicita de esta costumbre (véase Moreno et al. 2007, Moreno y Svoboda 2013).

En síntesis, el análisis zooarqueológico del sitio VH4 permitió ampliar el conocimiento sobre la subsistencia de cazadores-recolectores del bajo de Sarmiento para el Holoceno tardío final. En este sentido, para el lago Colhué Huapi se reconoció la importancia de los recursos dulceacuícolas sobre el guanaco, y de la relevancia de pesca que -aparentemente- fue una estrategia sistemática e intensiva. En futuros trabajos nos focalizaremos en: a) el análisis zooarqueológico de conjuntos en estratigrafía y de superficie de otros sitios ubicados en el lagos para corroborar las tendencias presentadas en esta contribución; b) comprender si la explotación de fauna dulceacuícola fue una estrategia estacional o anual, lo cual implicará la estimación de la estación de captura de percas a partir de la lectura de anillos de crecimiento de otolitos y escamas de perca (Svoboda 2013b); c) establecer 
los métodos de pesca poniendo a prueba la presunción de la utilización de redes, lo cual implicará el análisis tecnomorfológico de los pesos líticos y la estimación de las tallas de perca (Svoboda 2013a). Asimismo, el análisis arqueofaunístico de VH4 permitió entender los procesos de formación del sitio y su asociación con un cuerpo de agua que en la actualidad se halla ausente. Resta discutir, mediante estudios de base experimental, si el patrón esqueletal de peces y coipos podría responder a al transporte diferencial de los elementos por la acción hídrica.

\section{Agradecimientos}

Este trabajo se realizó con el financiamiento de CONICET y de la Facultad de Humanidades y Ciencias Sociales (UNPSJB). Agradecemos a Héctor Martínez por su hospitalidad y sus referencias de la historia del lugar. A Santiago Peralta González por la confección de mapas; a Mario R. Cabrera, Alejandro Scolaro, Cristian Pérez y Néstor García por el asesoramiento en la identificación taxonómica. Queremos agradecer a María Gutiérrez y Pablo Bouza cuyos comentarios ayudaron a comprender los procesos de formación del sitio y a los evaluadores que aportaron sus sugerencias. Lo expresado es responsabilidad de los autores.

Puerto Madryn, 7 de octubre 2016

\section{Bibliografía}

Aigo, J., V. Cussac, S. Peris, S. Ortubay, S. Gómez, H. López, M. Gross, J. Barriga y M. Battini. 2008. Distribution of introduced and native fish in Patagonia (Argentina): patterns and changes in fish assemblages. Reviews in Fish Biology and Fisheries 18:387-408.

Beeskow, A. M., H. F. Del Valle y C. M. Rostagno. 1987. Los sistemas fisiográficos de la región árida y semiárida de la provincia del Chubut. Delegación Regional Patagonia, SECyT, Puerto Madryn.

Behrensmeyer, A. K. 1978. Taphonomic and ecological information from bone weathering. Paleobiology 4:150162.

Binford, L. R. 1984. Faunal Remains from Klasies River Mouth. Academic Press, Orlando.

Butler, V. L. 1993. Natural Versus Cultural Salmonid Remains: Origin of The Dalles Roadcut Bones, Columbia River, Oregon, U.S.A. Journal of Archaeological Science 20: $1-24$.

Butler, V. L. 1996. Tui Chub Taphonomy and the Importance of Marsh Resources in the Western Great Basin of North America. American Antiquity 61 (4): 699-717.
Cabrera, A. L. y J. Yepes. 1960. Mamíferos Sudamericanos. Editorial Ediar, Buenos Aires.

Castro, A. 2010. "Rutas Indígenas y Arqueología en la provincia de Chubut". Facultad de Filosofía y Letras, Universidad de Buenos Aires, Argentina, 514 págs. Tesis Doctoral.

Césari, O., A. Simeoni. 1994. Planicies fluvioglaciares terrazadas y bajos eólicos de la Patagonia Central, Argentina. $13^{\circ}$ Symposium Latin-American Geosciences, Zentralblatt fur Geologie und Palaontologie, 1, 1993 1/2: 155-164.

Corbat, M. 2014. Una Aproximación tafonómica a los restos de peces en Laguna Llancanelo (Mendoza). Revista Chilena de Antropología 29: 116-121.

Coronato, F. 1994. Clima del nordeste del Chubut. Guía de Campo de la VII Reunión de Campo del CADINQUA, pp. 13-20. Centro Nacional Patagónico, Puerto Madryn.

Coronato, F. 2003. El problema de la desecación del lago Colhué Huapi desde la Geografía Histórica. Congreso Nacional de Geografía, 64 Semana de Geografía. Bahía Blanca.

Escosteguy, P.D., M. Vigna. 2010. Experimentación en el procesamiento de Myocastor coypus. M. Berón, L. Luna, M. Bonomo, C. Montalvo, C. Aranda y M. Carrera Aizpitarte. (Eds), Mamül Mapu, pasado y presente desde la arqueología pampeana, T. 1, pp. 293-299. Libros del Espinillo, Buenos Aires.

Escosteguy, P.D., M. C. Salemme y M. I. González. 2012: Myocastor coypus («coipo», Rodentia, Mammalia) como recurso en los humedales de la Pampa bonaerense: patrones de explotación. Revista del Museo de Antropología 5: 13-30.

Fabiani, A. C., L.S. Burry y A. H. Escalante. 2014. Análisis de polen y microalgas en sedimentos de la margen sur del lago Colhué Huapi, Chubut, Argentina. Una comparación entre orillas. Anales Instituto Patagonia (Chile) 42 (1):3551

Fontana L. J. 1976 [1886]. Viaje de exploración en la Patagonia Austral. Marymar Ediciones, Buenos Aires.

Frontini, R., P. Escosteguy 2012. Chaetophractus villosus: A Disturbing Agent for Archaeological Contexts. International Journal of Osteoarchaeology 22: 603-615.

Giardina, M. A. 2012 Intensificación en el sur de Mendoza: un enfoque avifaunístico. Archaeofauna 21: 219-234.

González, A. R. 1953. Las boleadoras, sus áreas de dispersión y tipos. Revista del Museo de la Cuidad de 
Eva Perón. N.S. Sección Antropología Tomo IV: 133-292.

González Díaz, E. F., I. Di Tommaso. 2014 Paleogeoformas lacustres en los lagos Musters y Colhué Huapí, su relación genética con un paleolago Sarmiento previo, centro sur del Chubut. Revista de la Asociación Geológica Argentina 71 (3): 416-426.

Grayson, D. K. 1984. Quantitative Zooarchaeology. Academic Press, Orlando.

Gutiérrez, M., C. Kaufmann. 2007. Criteria for the Identification of Formation Processes in Guanaco (Lama guanicoe) Bone Assemblages in Fluvial-Lacustrine Environnments. Journal of Taphonomy 5 (4): 151-176.

Klein, R. G., K. Cruz-Uribe. 1984. The Analysis of Animal Bones from Archaeological Sites. The University of Chicago Press, Chicago.

León, C., M. Bonomo. 2011. Índices de rendimiento económico de coipo (Myocastor coypus). Libro de resúmenes del II Congreso Nacional de Zooarqueología Argentina. UNICEN, Olavarría.

León, R., D. Bran, M. Collantes, J. M. Paruelo, A. Soriano. 1998. Grandes unidades de vegetación de la Patagonia extra andina. Ecología Austral 8 (2):125- 144.

Llanos, M. E. , S. J. Behr, J. H. González, E. N. Colombani, G. G. Buono y J. M. Escobar. 2016. Informe de las variaciones del Lago Colhué Huapi mediante sensores remotos y su relación con las precipitaciones. http://inta. gob.ar/documentos/informe-de-las-variaciones-del-lagocolhue-huapi-mediante-sensores-remotos-y-su-relacioncon-las-precipitaciones

Lyman, L. R. 1994. Vertebrate Taphonomy. Cambridge University Press, Nueva York.

Lyman, L. R. 2008. Quantitative Paleozoology. Cambridge University Press, Nueva York.

Mengoni Goñalons, G. 1999. Cazadores de guanacos en la estepa patagónica. Sociedad Argentina de Antropología, Buenos Aires.

Moreno, E. J., H. Pérez Ruiz. 2010. Evidencias de utilización prehispánica de recursos fluviales en la cuenca del lago Musters (Chubut, Argentina). En Actas del XVII Congreso Nacional de Arqueología Argentina. pp. 345350. Mendoza.

Moreno, E. J., A. Svoboda. 2013. Explotación de peces y guanacos en el interior de Patagonia central: aportes del sitio Delta del Arroyo Vulcana 1 (lago Musters, Chubut). Cazadores Recolectores del Cono Sur. Revista de Arqueología 7:49-68.
Moreno, E. J., B. Videla, H. Pérez Ruiz, L. Asencio y V. Leonforti. 2007. Búsqueda de indicadores de diversificación económica prehistórica en la Cuenca del Lago Musters (Chubut, Argentina). Primeros resultados. F. Morello, M.Martinic, A.Prieto y G. Bahmonde (Eds.), Arqueología de Fuego-Patagonia. Levantando piedras, desenterrando huesos... y develando arcanos, pp. 23-32, Ediciones CEQUA, Punta Arenas.

Moreno, E. J., H. Pérez Ruiz, F. Ramírez Rozzi, M. Reyes, A. Svoboda, S. Peralta González y M. Herrera Santana. 2015. Primeros resultados de los trabajos arqueológicos en el lago Colhué Huapi (Chubut). Cuadernos del Instituto Nacional de Antropología y Pensamiento Latinoamericano 24 (2): 133-137.

Moreno, E. J., H. Pérez Ruiz, y F. Ramírez Rozzi. 2016. Esquema cronológico y evolución del paisaje en el bajo de Sarmiento (Chubut). F. Mena (Ed.), De mar a mar, pp. 477-485, Ediciones CIEP/ Ñire Negro, Santiago de Chile.

Muñoz, S., F. Savanti. 1998. Observaciones tafonómicas sobre restos avifaunísticos de la costa noreste de Tierra del Fuego. Revista del Museo de Historia Natural de San Rafael 20 (1-2): 107-121.

Pizzolon, L. 2003. Lago Colhué Huapi. Catálogo de Recursos Hídricos, pp. 88, Secretaría de Energía, República Argentina.

Reyes, M. R., A. Svoboda. 2016. Un acercamiento a las artes de pesca a partir del análisis de los pesos líticos en el área de los lagos Musters y Colhué Huapi (provincia de Chubut). F. Mena (Ed.), De mar a mar, pp. 496-509, Ediciones CIEP/ Ñire Negro, Santiago de Chile.

Reyes M., S. Peralta González y A. Svoboda. 2016. Pesos líticos en el área del lago Colhué Huapi (provincia de Chubut): primeros resultados de los análisis tecnomorfológicos y distribucionales. En Actas del XIX Congreso Nacional de Arqueología Argentina, pp. 783785. Facultad de Ciencias Naturales e I.M.L., Universidad Nacional de Tucumán Serie Monográfica y Didáctica Vol. 54.

Ringuelet, R. A. 1975. Zoogeografía y ecología de los peces de aguas continentales de la Argentina y consideraciones sobre las áreas ictiológicas de América del Sur. Ecosur 2: 1-122.

Schuster, V. 2011. “Organización tecnológica de la cerámica de grupos cazadores-recolectores de la costa centro-septentrional de Patagonia (provincia del Chubut, Argentina)". Facultad de Ciencias Sociales, Universidad Nacional del Centro de la Provincia de Buenos Aires, Argentina, págs. 462. Tesis Doctoral.

Stahl, P. W. 1996. The recovery and interpretation of 
microvertebrate bone assemblages from a archaeological contexts. Journal of Archaeological Methods and Theory 3 (1): 31-75.

Stewart, K. M. 1991. Modern Fishbone Assemblages at Lake Turkana, Kenya: A Methodology to Aid in Recognition of Hominid Fish Utilization. Journal of Archaeological Science 18: 579-603.

Svoboda, A. 2013a. Disponibilidad cárnica, rendimiento energético y estimación de la talla de Percichthys trucha (perca criolla) a partir de la morfometría de huesos diagnósticos y su aplicación a los conjuntos ictioarqueológicos de Patagonia Central. Cuadernos de Antropología 9: 251-266.

Svoboda, A. 2013b. Método para determinar la estacionalidad de ocupación de sitios arqueológicos de ambientes fluviolacustres de Patagonia a partir de la observación de otolitos de percas. La Zaranda de Idea, Revista de Jóvenes Investigadores en Arqueología 9 (2):145-153.

Svoboda, A. 2015. “Los vertebrados pequeños en la subsistencia de cazadores-recolectores: una evaluación zooarqueológica comparativa para Patagonia Central". Facultad de Filosofía y Letras, Universidad de Buenos Aires, Argentina, págs. 343. Tesis Doctoral.
Svoboda, A. 2016. Tafonomía de peces: una experimentación sobre la alteración espacial en la costa norte de la provincia de Chubut. En IV Congreso Nacional de Zooarqueología Argentina, (comp.) M. Salemme, F. Santiago, A. Tivoli, M. Vazquez y A. F. Zangrando, pp. 58. Universidad Nacional de Tierra del Fuego, Ushuaia.

Svoboda, A., E. J. Moreno. 2014. Experimentación sobre los efectos de la meteorización en la supervivencia de elementos óseos de Percichthys trucha: implicaciones ictioarqueológicas para el sitio DV1, lago Musters (Prov. Chubut, Argentina). Revista Chilena de Antropología 29: 60-67.

Trivi de Mandri, M., L. S. Burry. 2007. Paleoambientes del Lago Colhué Huapi (Chubut, Argentina) durante el Holoceno reciente. Estudio palinológico Revista Española de Micropaleontología 39 (3): 205-214.

Zangrando, A. F. 2009. Historia Evolutiva, tiempos y subsistencia humana en la región del Canal Beagle. Una aproximación zooarqueológica. Sociedad Argentina de Antropología, Buenos Aires.

Zohar, I., T. Dayan, E. Galili y E. Spanier. 2001. Fish Processing During the Early Holocene: a Taphonomic Case Study from Coastal Israel. Journal of Archaeological Science 28:1041-1053. 